\title{
TEACHERS' CONCEPTIONS OF LEARNING PHILOSOPHIES: DISCUSSING CONTEXT AND CONTEXTUALISING DISCUSSION
}

\begin{abstract}
With the introduction of any new initiative into the mathematics classroom, there is often an assumption that it will produce visible and measurable effects in teaching approaches and pupil progress. Yet, there is a body of research that tempers such optimism, drawing attention to a series of mitigating factors, for example, the deep-seated nature of teachers' practices, their implicit or stated beliefs and values, and their lack of detailed awareness of how they perform in the classroom. Rather than make associative links between these factors and the success of the initiative, our intention is to examine the ways in which teachers are trying to interpret what the new scheme requires of them and how in turn, engaging with it causes them to re-describe both their pedagogic understanding and classroom practices relationally to earlier approaches. Employing data from a small project, we seek to examine four teachers' moves to grapple with this attempted shift from one teaching paradigm to another by considering how certain key terms serve to anchor the teachers' conceptions of themselves during this transition and find that their responses can be idiosyncratic and varied depending on the approaches in which they have been previously embedded. By using theoretical ideas from some neo-Marxist writers we examine these discursive shifts and their relevance to conceiving curriculum change. We suggest that the individual's teaching practice develops as a result of it being understood and enacted through a succession of ideological filters, each adding to the cumulative experience of the teacher.
\end{abstract}

KEY WORDS: teacher development, ideology, discussion, context

\section{INTRODUCTION}

Research in mathematics education is often predicated on identifying deficiencies in current practices as part of a rationale for implementing a new approach. Hargreaves (1996, p. 5) has suggested that educational research must demonstrate "conclusively that if teachers change their practice from $\mathrm{x}$ to $\mathrm{y}$ there will be a significant and enduring improvement in teaching and learning ...". Hence a history of research might be characterised as a series of papers and books, with many arguing the case for some sort of improvement. Yet looking back at any one time it is not easy to argue how we might assess the nature of this improvement over any given period of time. Meanwhile, teacher biographies are typically characterised by engagements with a number of teaching approaches throughout any one career. Each shift from one to another entails mathematics being framed in a slightly different way that perhaps results in a different teaching style and, perhaps also, in a different conception of mathematics. Elements derived from each phase feed into composite experience and contribute to that teacher's mode of practice and emergent, and perhaps convergent, professional identity. These elements might be attributed variously to fashions in school practices, learning theories, assessment preferences, career phase of the individual teacher, etc. The shifts in teaching approach would normally be locally negotiated on the basis of some supposed improvement on the previous model. The term "improvement", however, can be 
understood in many different ways and resists stability across time, space and circumstances.

The aspect that interests us here concerns the sort of identifications that teachers might have with successive phases. How might adjustments to practice be understood when a teacher is confronted by new discursive styles being applied to his practices? This paper discusses such concerns in relation to a group of secondary mathematics teachers participating in a small British teacher development initiative that sought to better understand better how teachers, ${ }_{2}$ schooled in differing sets of philosophies and practices, respond to a new, alternative model. Data presented is analysed as evidence of the teachers" "identifications" with a new paradigm, and how these identifications are made through specific traits of that paradigm. The paper theorises such identifications through the work of the neo-Marxist writers, whose work is rooted in Marx's notion of dialectical materialism in which the world shapes itself around the descriptions made of it. This enables us to depict a world whose qualities and compositions shift as we engage with it. Such themes have implications for how we think about initiatives designed to work at creating consensus in teaching approaches. We question the efficacy of a research agenda predicated on encouraging teachers to align themselves with a particular model or philosophy of practice. In particular, we suggest that, within any curriculum implementation, both teacher self-perception and the curriculum itself are reconstituted such that any supposed convergence to an end-point is disrupted.

\section{CONCEPTUALISING CURRICULUM IMPROVEMENT}

\section{Brief review of mathematics education literature}

With the introduction of any new initiative there comes an implicit assumption that it will bring improvement over the previous regime. There are a number of studies (e.g. Hickey, Allison, \& Pellegrino, 2001; Swan, 2000) that describe curricular innovation and the (modest) benefits that follow. More specifically, teachers' orientations to teaching mathematics are identified as influential factors in mediating the strength of an initiative's effect. Evaluations of the English National Numeracy Strategy refer to teachers' deep-seated beliefs, which are left largely unchallenged (e.g. Brown, Askew, Millett \& Rhodes, 2003) such that structural changes can be "bolted on" to existing practice (Galton, 2002). Similarly, Brown, Millet, Bibby, and Johnson (2000) have asserted that any such development will have multiple interpretations made of its impact. Local context also appears to influence the nature of classroom implementation: specifically this could be teachers' perceptions of their school's priorities within the wider education system (Kynigos \& Argyris, 2004; Ng, Lopez-Real, \& Rao, 2003) or their beliefs about pupils' needs beyond mathematics (Sztajn, 2003). Senger (1999) and Skott (2001), meanwhile, provide models that help to illuminate shifts in teachers' thinking and practice as a recursive interchange between beliefs and how they talk about teaching and experimentation. One specific aspect that has drawn attention is the quality and variation of interactions observed in whole class teaching (e.g. Brown et al., 2003; Burns \& Myhill, 2004). Still other pertinent and diluting factors include teachers' lack of 
detailed awareness of how they operate (Sahin, Bullock, \& Stables, 2002; Torrance \& Pryor, 2001) and for how long they have been teaching. Inexperienced teachers are more likely to engage fully with new curricula (Remillard \& Bryans, 2004), whilst experienced teachers can find it very difficult to alter practice (Romberg, 1997) as personal beliefs about practice are based on compelling evidence derived from daily classroom experience (Handal \& Herrington, 2003).

We take forward the idea that asking teachers to move from one teaching approach to another can never be regarded as a straightforward substitution (cf. Fullan, 2001). Nevertheless, for those charged with setting policy, there is often a perceived obligation to do something. And often this involves doing something big. In the United Kingdom, New Zealand and Australia ${ }_{2}$ governments have prescribed detailed curricula for students and teachers alike, along with associated industries of preparation of materials to mateh. In terms of research literature, however, we find considerably more information readily available about the effectimpact of major curriculum reform in the United States, where there is also a considerable emphasis on the widespread adoption of new curriculum materials as a primary strategy for improving mathematical education (Remillard, 2005). And, we shall suggest, this research has influenced the parameters through which we understand curriculum reform and related research more generally.

The next section considers US reform in relation to how the movement shapes curriculum change and research literature. We question the common assumption that research is about encouraging movement towards some improved conception of teaching on the grounds that "improvement" is not a universal term. Rather, we endeavour to show how US reform has shaped research and practice domains terrain-in particular ways with commensurate conceptions of improvement. We offer an alternative conception of change in recognising that "we move to a future which is unforeseeable from the perspective of what is given or even conceivable within our present conceptual frameworks" (Lather, 2003, p. 262).

\section{US "Reform" as ideology: research seen as encouraging movement to an ideal}

US reform, more generally $y_{2}$ is defined in relation to NCTM guidelines and is,are for many teachers, seen as the transition from a transmission to a constructivist pedagogical approach (e.g. Fennema \& Nelson, 1997). Constructivism, which has dominated international mathematics education research for the last two decades (Steffe \& Kieran, 1994; Brown, 2001), is characterised by "genuine mathematical problems for students to solve" (Lloyd, 1999, p. 228) and a focus on "conceptual understanding" (Wilson \& Goldenberg, 1998, p. 269). Simon and Tzur (1999) and Tzur, Simon, Heinz, and Kinzel (2001) provide more recent examples in which research is conceptualised as tracking progress towards some improved state of affairs. Many other studies focusing on how teachers respond to curriculum changes (e.g. Remillard \& Geist, 2002; Van Zoest \& Bohl, 2002) centre their analysis on individuals shaping their practice in response to the perceived reform agenda, an agenda with which the authors positively identify and to which they readily subscribe, albeit with resistance from some quarters, such as "veteran" or "traditional" teachers who are unable to shift so fundamentally in terms of their beliefs as to what it is to be a teacher (Cohen, 1990; Wilson \& Goldenberg, 1998; Lloyd, 1999). 
Such reform, however, does not offer a trajectory with universal appeal or applicability. The "inquiry" methods associated with constructivist reform, characterised by greater learner and teacher autonomy, would be less acceptable in many Eastern or Pacific cultures where curricula, teacher/student roles and the collective good are defined differently (e.g. Brown et al, 2006). Further, the alleged autonomy understood within the "reform" agenda conflicts with the reality teachers have come to accept in other Western countries, assessed as they are through legislative documentation and recognised through the filter of their compliance with this. In the UK, for example, student centred pedagogies emphasising problem-solving, investigations and project work dominated curriculum reform agendas some thirty years ago, but a more recent backlash has resulted in prescribed curricula for both teachers and pupils in which student centred approaches have become tightly structured (Brown \& McNamara, 2005). Reasons cited for this backlash included right wing government ministerspoliticians (such as Kenneth Clarke, a Conservative Minister of Education speaking in 1996) claiming that the average teacher could not teach to such high-minded ideals and left wing commentators arguing that child-centred-ness merely replaced overt regulation with a form of covert regulation (Walkerdine, 1984). In this respect, conceptions of improvement are very much a function of the country, or even local community, in which they apply and the state of affairs prevalent there. And it is this sense of contingency that underpins this present paper's focus on adjustments to new paradigms. In particular, we claim it is unhelpful to suppose that we could identify trajectories of improvement that apply across all people and all phases of development. There is always a cost in the form of suppressions resulting from such generalist suppositions. Consequently, we seek to build a theoretical frame that permits an alternative to consensual aspiration. Further, we suggest that such consensual aspirations and alignment with them are not always so easy to grasp through the immediacy of everyday practice. It is on this point that we invoke some contemporary writers who have focused on how collective identities evolve.

\section{Rethinking consensus}

Mouffe (2005) has strenuously resisted the idea of human progress as being shaped by ideals relevant across all communities. Mathematics education, for example, would be seen as culturally dependent with each ideology predicating an alternative conception of mathematics. Laclau (2005) has rejected the notion of the "people" as a collective actor, and $_{2}$ by extension ${ }_{2}$ the possibility of a research "community" or a set of governments being able to define a common interest with regard to the purposes of school mathematics. Instead, he has examined the nature and logics of the formation of collective identities and suggested that such collectives be seen as being held together through identifications with specific populist demands. Althusser (1971) focuses on how the individual understands herself through ideological filters. That is, the individual recognises herself in some discourses but not others. For example, an individual American teacher may truly believe that she is subscribing to reform agenda and following such approaches in her practice, whether or not others see it this way (e.g. Cohen, 1990). But, there is always a gap in this identification, a distance between the person and the story in which she sees herself. This gap stays there. Althusser (1971) is 
not persuaded by consensual aspirations where difficulties are ironed out. And surely someIt seems to us that American teachers are sceptical about reform projecting them to the top of international league tables or even that everyone will-and do not always agree with agree with the content of that ambition. Time does not necessarily make alternatives more attractive or comprehensible. Althusser sees the supposition that you could get to a consensual ideal beyond conflicting ideologies as the biggest ideology of all. Finally, we shall later refer to Rancière (2004), who examines how particular ways of understanding life, and the cultural forms that prevail, are functions of time- and culture-specific conditions of possibility. Here we are alerted to the possibility that successive cultural forms derive their meaning from earlier cultural configurations rather than from any supposed underlying truth of practice. The individual's immersion in successive ideologies of practice might be understood as a task of crafting the various ideologies together into a functional whole in some more or less personal way, rather than being immersed in one distinct ideology rather than in another.

US "reform" functions as an ideology insofar as it has set key parameters shaping discussion relating to curriculum innovation. It is a conception of improvement often presented as universally beneficial but actually it is culturally specific. It defines a professional space governed by certain assumptions as to how improvement might be achieved, whilst the limitations of its validity remain peripheral to this definition. Further, according to Sztajn (2003, p. 53), even within that culture: "Based on their concepts of students' needs, teachers select which parts of the reform documents are appropriate for their students" which translates as "children from upper socioeconomic backgrounds get problem solving, those from lower socioeconomic backgrounds undergo rote learning" (ibid). Viewed internationally, however, even such variation might be regarded as modest, framed as it is within the parameters of national boundaries, compulsory schooling infrastructure, economic status and a host of other societal assumptions. So as we proceed ${ }_{2}$ we need to be cautious in observing how such assumptions have slipped into the apparatus for curriculum reform research more generally.

\section{Teacher/curriculum co-construction}

Yet even affinity with an ideology does not necessarily fix the mode of association or how that is viewed. In her study Remillard (2005, pp. 215-223) examined alternative ways in which teacher/curriculum interfaces are understood within the research literature. She contrasted "following or subverting" a curriculum text with "drawing on" a curriculum text or "interpreting" a curriculum text. In these three alternatives, the text is present in some form and teachers respond to it as stuch. Finally, however, Remillard considered how curricula might be understood as teachers participating with the text. We shall consider this conception in greater detail here. For a teacher "enacting" a curriculum in this mode, she suggested that teacher and curriculum might be seen as mutually constitutive. Here, curriculum use is understood as participation with the text (pp. 221223). She identifies this with "Vygotskian notions of tool use and mediation, wherein all human activity involves mediated action or the use of tools by human agents to interact with one another and the world" (cf. Cole, 1996). Such an approach is familiar within mathematics education research (e.g. Lerman, 2000; Blanton, Westbrook, \& Carter, 
2005; Goos, 2005). But how might we unfold the features of this mutual constitution of teachers and curricula? Understood in terms of Foucault's (1989) notion of "discursive formation", both teacher and curriculum would be functions of how they are implicated in the stories that unite them. Both change as a result of curriculum development activity. Remillard (ibid) identifies some studies where teachers change or learn from their use of resources (Lloyd, 1999; Remillard, 2000; Van Zoest \& Bohl, 2002). Krainer (2003) outlines an action research approach to national reform in Austria where teachers are left to decide what is best for them. Yet teacher change can also be understood as being the result of increased compliance with respect to a curriculum initiative.

A core assumption of this paper is that aspirations to consensus can suppress the specificities of alternative needs, responses, etc. Brown and McNamara (2005) provide an account of how trainee and new teachers in the UK begin to include official curriculum descriptors into accounts of their own practices as they move through the accreditation process. The conception of identity introduced here, however, does not necessarily favour compliance with the dominant group. Conceptions of self are governed by a tussle between achieving personal aspirations and meeting external demands. The task of socialisation entails the teacher gradually introducing social/official language into her self-descriptions. She becomes increasingly implicated in official accounts of her practice as she begins to recognise herself in such accounts and to describe herself in those terms. And in so doing, she loses aspects of her earlier, perhaps more personal, conception of self. Teachers saw this as necessary from the point of view of their accreditation as teachers ${ }_{2}$ yet found the discourse highly prescriptive, albeit a form of prescription that released them from the need to make so many content decisions in a curriculum area where often they had in the past lacked confidence in their own capabilities. The research perspective offered in this paper similarly attempts to weigh up the relative advantages of achieving personal aspirations or fulfilling external demands, rather than supposing external demand is to be favoured. Further, Althusser (1971) argues that there may be some fracture between perception of immediate actions and the external discourse to which the individual supposed they had identified. That is, individuals misread themselves as being supportive participants of some collective enterprise as defined externally, for example, conforming to US reform or following National Numeracy Strategy correctly. By resisting notions of the curriculum as being ready constituted, and by contesting researchers who assign roles for teachers in relation to such frames, we can assign a more prominent role in curriculum development to the individual teacher. The constitution of curriculum is contingent on teacher participation. The curriculum is not a thing in itself ${ }_{2}$ since the teacher's participation can radically determine its efficacy. Thus our attempt in this paper is to resist describing curriculum development from the point of view of how teachers align themselves or not with an overarching rationale or model such as reform. Alignment by a teacher with a new curriculum is not in itself necessarily to be viewed as success, since improvements are a function of the ideological stance being assumed. Both teacher and curriculum change through any curriculum initiative, as do the parameters through which those changes are understood (Schön, 2003).

In the next section we describe a curriculum initiative and an associated research project. In the subsequent section we look at some accounts of teachers reporting on their experience of participating in the initiative. We conclude with some analysis of this data. Our purpose is not to establish how the curriculum per se has been implemented but 
rather to better understand how both the teachers and curriculum have been transformed as a result of the initiative. We show how the curriculum is understood and enacted differently according to the teachers' previous experience.

\section{A CURRICULUM INNOVATION}

\section{Realistic Mathematics Education}

Since the advent of international comparisons (e.g. The Third International Mathematics and Science Study (Harris, Keys, \& Fernandes, 1997)) governments have been jockeying for a better position in the resulting league tables. The Netherlands were particularly successful and were widely seen as providing an achievable model upon which other Western countries could base their aspirations (de Lange, 1996). For a number of years some schools in the Netherlands have pursued practices based around Realistic Mathematics Education (RME). RME is rooted in the work of Freudenthal (e.g. 1991). In his view, when constructing a school mathematics curriculum, educators need to be aware of two basic principles. Firstly, mathematics needs to be seen as connected to the learners' world. Hence realistic refers to problems, which are meaningful or imaginable to the learner. The contexts are there to help them make sense of the work, and to keep it close to their reality, though contexts are chosen initially for mathematical rather than social reasons. Secondly, mathematics needs to be seen as a human activity and central to this is the idea of guided reinvention (Gravemeijer, 1994). This approach privileges the informal strategies that students bring and learners make small steps in a context which guides learning toward more formal perspectives.

Materials in English, based on RME principles have been produced within a collaborative venture between the Freudenthal Institute and the University of Wisconsin in the USA. The resulting scheme, "Mathematics in Context" (MiC), was created to support a project undertaken by the University to introduce RME principles into a pilot curriculum in Wisconsin; it presents as a series of textbooks.

\section{A Curriculum Initiative and some Associated Research Projects}

The study reported here was an offshoot of a major Gatsby funded initiative based on trialling MiC materials in British schools (Eade \& Dickinson, 2004-2007). It was a smaller scale pilot for a project, funded in the following year by the UK Economic and Social Research Council (Torrance \& Hanley, 2005-2006) and was-, designed to track the shifting perceptions of the teachers involved in the larger study. In particular, this pilot study (2004-2005) asked how the teachers accommodated their exposure to a new paradigm within their existing conceptions of practice. It tracked the teachers through their first year of participation and sought to document changes to the ways in which they accounted for their practice with reference to old and new paradigms.

Prior to the introduction of RME to Manchester schools, a significant number of teachers in the sample had been introduced to a Whole Class Interactive approach to 
Teaching (WCIT) (Harrington, 1998). In this approach, the teacher's task was to facilitate a learning environment that sought to maximise opportunities for students to contribute to an evolving group account of the mathematical situation being considered. Having posed a question to the class she the teacher then sought to ensure that a significant number of children were included as the teachershe sought to help the children to craft a composite story out of the diverse comments that they offered. This discursive generation provided children and teacher with a frame within which they could begin to share ways of talking in relation to mathematical stimuli. Here, rich discussion was seen as evidence of shared mathematical construction and so a common objective for teachers working within this approach was to work toward extended conversations. Whilst familiar mathematical concepts would be touched on within such discussion the teacher sought to promote the students' own mathematisations. That is, the students were encouraged to encapsulate the mathematical phenomena in their own terms. This provided the basis for later translation into more conventional terminology. Such an approach had been influential for some of the teachers involved and shaped their practice in significant ways.

Yet, for other teachers, WCIT had not figured in their experience prior to the project. They had been trained educated elsewhere or before this interest held currency. The sample therefore comprised a variety of earlier practices. Further, in the period that the study covers, a government-sponsored initiative, the National Numeracy Strategy, that had earlier been introduced in to primary schools, was being extended into the secondary curriculum. This framework featured overtly programmatic aspects that entailed crafting all lessons to a prescribed format. Whilst discussion featured as a key component of these lessons, this discussion was contained within particular parts of the lesson and was targeted at specific elements of the National Curriculum. TAs steh there was some potential conflict for teachers pursuing WCIT objectives as they sought to participate within this emerging frame. But ${ }_{2}$ more generally, the implementation of this framework had not been embraced with consistent enthusiasm across the teaching force. This resulted in uneven early implementation.

This need to reconcile alternative paradigms was intensified as schools in the study began their participation in the current project. At least three paradigmatic understandings of curriculum innovation were represented: the National Numeracy Strategy, an administrative framework designed to enable teachers to introduce mathematical concepts as defined in the National Curriculum (Department for Education and Employment, 2001); WCIT, a discursive teaching style derived from the diagnostic teaching approach (e.g. Bell, 1993); RME, a philosophy of learning.

\section{Methods}

We examine how teachers move from one paradigm to another by looking at how certain key terms serve to anchor conceptions of the schemes during this transition. The four teachers represented anonymously here, Jennifer, Jonathan, Lucy and Michael, were part of a larger cohort $(\mathrm{n}=12)$ that undertook to participate in the first year of the Gatsby funded project. The teachers were representative of the sample of six secondary schools in Manchester who agreed to use MiC materials with at least two classes of children aged 11-12. Each of the four was from a different school, these varying in terms of pupils 
being either of mixed, or single sex and in their ethnic, social and religious background. of their intakes. In addition, the teachers attended regular 'training' days at Manchester Metropolitan University, where the principles of RME were diseussed-andas well as the MiC materials_were discussed, together with teachers' pedagogic concerns in relation to these. Training days occurred at six weekly intervals. Guests from both the Freudenthal Institute and the University of Wisconsin participated on two of these days and visited project schools. In the discussion that follows, the term MiC will be used to represent both the philosophy (RME) and the associated classroom materials.

The intention was that all participating teachers should be interviewed at the beginning and at the end of the first year of the project, 2004/05. Eight teachers attended both interviews. Each interview lasted approximately half an hour. The interviews were semi-structured in form and were designed to ascertain teacher beliefs with regard to teaching but more particularly $_{2}$ how these beliefs evolved as a result of participation in the initiative. They focused on how the teachers understood the key components of their own teaching, the skills that they thought were important and how these shifted as MiC was introduced. The resulting transcripts were analysed by two researchers and two issues were found to arise consistently as themes that marked shifts in practice. As will become clear in the following excerpts, the ways in which the two particular words, discussion and context, were discussed provided good illustrations of teachers repositioning themselves. These words were pivotal words in the teaching approaches being considered, especially since as seen above WCIT focused primarily on how mathematical ideas were developed collectively through classroom discussion. As steh, Tteacher objectives could be understood in relation to how such discussion was crafted. Yet such crafting needed to be adjusted when MiC objectives were introduced where specific features of discussion came to be seen as more important. Meanwhile, the prominence of "context" as a key word in MiC resulted in mathematical ideas being processed through alternative pedagogical devices. Whereas ${ }_{2}$ for teachers trained in other paradigms, both words became prominent tools in re-describing practices. The specific quotes were chosen as they seemed to capture most clearly the essence of what the teachers were trying to say; overall their transcripts showed high internal consistency of meaning. More particularly, however, our analysis here is directed at showing how the two key terms were used in distinguishing aspects of shifting practices. Our intention for this paper was to examine how the teachers understood their broader practices in relation to their deployment of alternative paradigms but through aspeets that were immediately graspablethrough their use of these terms and surrounding material. We assumed that there would be some gap between the teachers' practices and how they described them as well as some gap between each of these and alignment with MiC practices. As suchthus, we sought to ascertain how much we could say about these gaps as a result of interrogating the teacher accounts of their practice and of the alternative paradigms.

\section{SOME TEACHERS' ACCOUNTS OF THEIR EXPERIENCE OF TRIALLING $M i C$}

\section{"Discussion"}


Here we seek to give a flavour of some teachers' perception of how their understanding of "discussion" shifted as they participated in the study and sought to be governed more by their understanding of MiC principles.

Jennifer works in a school where the mathematics department is open to trying new approaches, the predominant current pedagogy being WCIT, with the National Numeracy Strategy taking a relatively backstage position. Looking back, this is how she described her teaching before her involvement in MiC:

Before I was quite happy to discuss all lessons.... There was just one question in the class and we worked towards that one.... We tried to develop skills in prolonging discussion and some of us got quite good at it. (Interview 1)

Jennifer began to realise that her discursive style was not a great fit with the newly introduced $\mathrm{MiC}$ scheme. As she tried to accommodate aspects of this new approach she experienced some discomfort:

I'm torn with: Are we now rushing through the materials instead of discussing? ... What's hard now is stopping the discussion. Or deciding what's worth sharing as a class and what's ok just to leave to discuss in pairs.... Last lesson I started wondering who was the discussion for. Is it just that I need to be involved? Is it for the few who know what's going on? Is it to give ideas to others who are stuck? And do we need a long discussion all the time? (Interview 1)

This discomfort continued throughout the year, which seemed to imply difficulties in being able to process her practice through the two paradigms simultaneously:

I found myself wondering: What are we discussing? Are we just discussing the answer or are we discussing the strategies.... Before I was quite clear what I was discussing and now I'm doing this. I'm not sure any more. (Interview 1)

Jonathan had also been involved with the local development of WCIT before embarking on the project:

I think what we had been doing was we'd been getting a good question, getting the kids to work on it for a while and then having a long discussion and hearing lots of different view points and then trying to come to some sort of conclusion about which is the most efficient method.... (This) would take the lesson, ... maybe lesson and homework. (Interview 1)

Equally, Jonathan has found himself having to make similar adjustments to his teaching, so as to accommodate the MiC scheme, though his inner tension in doing so appears to be less evident than it was for Jennifer:

I've started to try and make it snappier and pacier and you know cut off a discussion when I wouldn't normally cut it off.... I'm kind of thinking that a lot of the important and most useful comments come out at the beginning anyway and sometimes when a discussion drags on. It's other people repeating what's already been said or making refinements that actually don't improve the overall understanding. (Interview 1)

Later on, Jonathan seems to have become comfortable with this change:

I've stopped feeling the need for closure on topics. I think, you know, at the very early stages it was like walking through every question and ... having to have everyone happy with the answer before you've 
moved on and I'm very much less bothered by that now and I think the class are more used to doing that. (Interview 2)

Lucy entered the project from a rather different starting point. In her background "normal classrooms" had assumed a framework where discussion seemed to fit around the edges of more individually focused activity triggered by some teacher input:

In normal classrooms you have your introduction where you kind of bounce ideas and then the kids kind of get on with it, but I don't encourage them to be working with each other as much because obviously I don't think the focus is on too much paired working and group working.... I have got to see how that individual is doing so she has to work on her own. $\quad$ (Interview 2)

Clearly for Lucy the journey has been in a different direction. Discussion has become a vehicle for pupils' learning and in a way that has both surprised and delighted her:

MiC ... is all the time (asking), "how?" or "why?" or "where did that come from?" So my questioning has changed and my taking answers, leaving them there for a few minutes ... allowing them to get it wrong.... They bounce so many ideas off each other so much and they help each other so much. (Interview 2)

Michael in describing his teaching before the project, made no reference at all to discussion as such:

I have questions that I'm going to model and I expect two or three to be done. Then we'll go through the answers ... It's just ... is the word didactic, where I would say "this is the way, and this is what I want you to do". (Interview 1)

However, once he has started using the MiC materials, discussion has clearly become a significant feature in these classes and in a way that is very comfortable:

I'll have moved around the room when they're doing their questions and I'll see particular things that I want to talk about and I will ask those kids particularly to give me their answers.... I'd say just take what kids say and leave them hanging there. And if no-one comes up with a contradiction or a problem with what is offered, then just leave it and move on and don't bother too much about being the font of all knowledge. (Interview 2)

Thus we have four teachers providing thoughts on how the role of discussion changed as a result of encountering $\mathrm{MiC}$; two who, in a sense, were seeking to regulate the extensive discussion that they had previously promoted, and two who were interpreting $\mathrm{MiC}$ as an approach where discussion would figure more prominently than before.

\section{"Context"}

We now offer some other data in which the same four teachers provide comments that reveal how the notion of context changes in the same period.

Jennifer was rather less forthcoming about context, since her WCIT base point resulted in her evaluating her own lessons primarily from the point of view of how discussion was generated, yet, in the second interview, she made the following comment: 
I'm trying to take them back to the context when it feels you know that they are not accessing what's happening.... Developing mathematical ideas through contexts that are real to kids, not necessarily real life but something they can relate to so that that is an entrance to a problem.

(Interview 2)

Jonathan, looking back, thinks that before the project:

The talk that would have been going on in a non-MiC classroom might be more related to "Do you just do that to the top and multiply by this and divide by that? And that's how you do them". So even if ... you had actually started the topic with a context, the discussion would be a discussion of the maths out of the context.

(Interview 2)

Whereas after several months using the MiC materials Jonathan can see that context could have a different function:

The context thing is the thing that stands out most; that is they learn more with maths in a context that they can get their teeth into it. They can get a grip on it, rather than just working with pure numbers.... We're still working with maths when we're doing MiC but I think ... that the context and the relevance of it to them makes it easier for them to engage in it. (Interview 2)

During the project Lucy became aware how much of her previous teaching had centred on algorithms and how these perhaps did not lead to enduring learning. In this example she reflects on how she taught the area of a rectangle:

"Right well you can see that there's so many squares on that row, and there's so many rows, and therefore the area is such and such"... Then you'd clarify it. Then you'd write the formula on the board and then we'd practice various different problems using that formula... It kind of just brought me back to thinking they've heard this, but they've not understood it, and therefore now they're using it incorrectly, which then made me think, maybe we shouldn't be giving these algorithms. (Interview 1)

Equally pupils did not find the algorithms useful:

They'd come in "but how does this relate to, you know, what's this got to do with my life?" (Interview 1)

In the second interview, Lucy saw that MiC was offering an alternative:

The context - if the kids can grab that context they can understand what it is starting to talk about. They can then begin to understand how to solve it.... Then once it got to the stacking cups, even though it got more difficult, the kids could still access it and begin to solve it in their own way.

(Interview 2)

Michael expressed quite a degree of dissatisfaction with his usual teaching from very early in the project - this centred on his attempting to work in the abstract:

I usually start with a context myself and work within one but then unfortunately the resources that I have to hand such as texts that are produced commercially have quite poor context or they move into the abstract very quickly and you then end up running around the length of the classroom patching things up. (Interview 2)

The MiC scheme represented a panacea to this situation:

I really like it because ... instead of being a load of abstract, stand-alone skills, you can see that people might want to see ... how much carpet they'd need to cover a room.... There's a natural interest in it.... I 
found it very interesting that thinking from Utrecht was that very few individuals will ever need to or will have the ability to move into fully abstracted generalised mathematics, which is fair enough. But our education system predominantly tries to push people there, which seems very bizarre. (Interview 2)

\section{ANALYSIS OF DATA}

In examining the data presented above, we see our task in terms of pinpointing how the words offered by the teachers demonstrate their attachment to, or identification with, a particular way of comprehending their own teacher practice. Yet we need to exercise care in supposing that a shift in the teachers' terminology indicates an adjustment to their underlying practice. Indeed we prefer to avoid the implied distinction between surface and depth, or between evidence and supposed truth. Such couples are specific to particular and alternative discursive domains rather than universal. For example, Hammersley (1997) argues that the evidence based practice movement privileges research discourse over the discourse of professional experience. The data in these two domains, he suggests, would be constructed rather differently and would be linked to a broader reality through alternative procedures. We thus focus on the teacher speech and the self-conceptions implied in this and consider this speech in relation to the alternative practice/research/policy paradigms. In an interview Rancière (2004) was asked what he felt about the common assumption made in the social sciences that a surface appearance was associated with something hidden. He was specifically addressing how ${ }_{2}$ in works of art $_{2}$ the presentational dimension can be seen as being associated with a deeper meaning. Rancière (2004, p. 49) responded in the following terms:

I always try to think in terms of horizontal distributions, combinations between systems of possibilities, not in terms of surface and substratum. Where one searches for the hidden beneath the apparent, a position of mastery is established. I have tried to conceive of a topography that does not suppose this position of mastery. It is possible, from any given point, to try to reconstruct the conceptual network that makes it possible to conceive of a statement, that causes a painting or a piece of music to make an impression, that causes reality to appear transformable or inalterable.

We would like to attempt a substitution in which Rancière's reference to painting or piece of music is replaced by a particular scheme for mathematics teaching or a socially derived configuration of mathematics education practice. With this analogy, the recognition of such a scheme is a function of the history into which it is being inserted. Yet the experience of this history will be different for each individual according to how the individuals have accessed this history through a variety of alternative cultural forms. To take Hammersley's (1997) example cited above, alternative discursive forms are alternative forms of life and cannot readily be compared side by side. The parameters through which these discursive forms are understood are time and experience dependent. And such parameters derive from successive manifestations of the ideological filters that govern teachers' and researchers' participation in life (Althusser, 1971). Rancière (2004, p. 50) continues:

The visibility of a form of expression as an artistic form depends on a historically constituted regime of perception and intelligibility. This does not mean that it becomes invisible with the emergence of a new regime. I thus try at one and the same to historicise the transcendental and to de-historicise these systems of 
conditions of possibility. Statements or forms of expression undoubtedly depend on historically constituted systems of possibilities that determine forms of visibility or criteria of evaluation, but this does not mean that we jump from one system to another in such a way that the possibility of the new system coincides with the impossibility of the former system. In this way, the aesthetic regime of art, for example, is a system of possibilities that is historically constituted but that does not abolish the representative regime, which was previously dominant. At a given point in time, several regimes coexist and intermingle in the works themselves.

If we accept the analogy of approaches to mathematics teaching with what Rancière terms artistic forms, we also take on the parallel notion of mathematics, and more specifically mathematics curricula, being articulated through cultural regimes, or particular systems of conditions of possibility.

Specifically, our data have been centred on the teachers' use of the terms "discussion" and "context" and how this use defined relative allegiance to alternative paradigms. Yet we are arguing that such terms do not function as "structuralist" signs, as described, for example, by Saussure (1966), Piaget (1971) and Levi-Strauss (1989). In such conceptions each signifier is firmly tied to a well defined signified to form a sign. Rather $_{2}$ we are arguing that signifiers derive their meaning through a play of difference with other signifiers (e.g. Derrida, 1978). This alternative conception of "signifier" has been discussed in relation to mathematics education elsewhere (Brown, 2001). The terms are shaped more by discursive parameters than by some notion of underlying practice. Such a shift we feel better reflects teachers' responsiveness to policy where the discursively formed rationale for teaching is built from the language of the many paradigms that have had an effectimpaeted on the teacher's understanding of teaching and of their practical engagement with it. And such practical engagement is never precisely anchored by discursive accounts. As already suggested, there is always a gap between the discipline of following a particular ideology and the agency of more personal action. More particularly, however, there is a gap between the teacher's rationale and practices offered in respect of this. Brown and McNamara (2005) and Brown, Atkinson, and England (2006) provide detailed discussions of this.

At the outset of the curriculum initiative, the teachers did not have an overall sense of what it might be to be a teacher following RME principles. Having spent a period of time between the two interviews they grasped it some understanding through particular traits that they had begun to identify as significant. "Discussion" and "context" emerged as two key words that acted as both variables in assessing practice and levers in developing it. Consequently, these provided a useful research instrument in grasping how the teachers revised the map of their teaching domain. With respect to the teachers' conception of the term "discussion", however, we find teachers coming from very different directions. For two teachers (Jennifer and Jonathon), it represents an aspect of their practice that is already well developed yet needs to be reconceived in relation to the objectives of the MiC scheme. For the other two teachers (Lucy and Michael), it represents, at least in hindsight, a deficiency in their previous practice. $\mathrm{So}_{2}$ in respect of their attempts to connect with MiC, "discussion" emerges as a buzzword that commands a key filtering role in the register that shapes the teachers' new practice. They identify with it as a component of teaching as they now understand it. All four teachers can subscribe to it as an important ingredient in this new conception of teaching. There is some evidence that for all four teachers the re-conception of "discussion" also 
reconfigures the composition of activities that together comprise their "teaching" and that they appear to see these changes as improvement.

Jennifer questioned the target of her earlier faith in discussion and now wanted to be clearer about what discussion was getting at and how it might be better shaped to meet those objectives. Jonathan wanted to be "snappier" and "pacier" rather than let the discussion "drag on". He also began to see less need to include everyone's perspective perhaps a result of being governed more by a clearer advance sense of what he was trying to achieve as teacher. Meanwhile, the other two appeared to be converts who had previously marginalised "discussion". Lucy, in sharp contrast to Jonathan, was now delighted that children could "bounce ideas" and had the opportunity to "get things wrong". Michael, meanwhile, similarly seems to have become more relaxed about not achieving closure rather like the earlier stance adopted by Jennifer. SoAs such MiC functioned differently as a motivator for the two pairs of teachers: it seemed to provoke their seeing future improvements as movement in opposite directions to each other. IAs stch it seemed that while the teachers' shifting conceptions were not sharing a trajectory to a common position, each of them was in the process of some pedagogical identity shift. Their descriptions of themselves engaging with MiC were of a conception of teaching defined differentially to their previous practices. Personal improvement was seen alternatively as "less but more managed" discussion, as against "more" discussion. Their sense of their own teaching was in terms of the next step for their own improvement in relation to where they perceived themselves being before. TAs steh the mathematical activity produced in this new teaching configuration was not pinned down or seen equivalently by the four teachers, though on the face of it all were apparently convinced by their MiC-inspired approaches.

The notion of "context" functioned rather differently. For the two teachers already schooled in discursive approaches (Jennifer and Jonathon), "context" was seen as making mathematics more engaging by providing entrances accessible to pupils through employing more informal strategies. It provided a clear alternative to promoting discussion for its own sake as in WCIT. In this way, context was now seen as a vehicle for mathematical understanding not an additional layer of difficulty. For the two other teachers (Lucy and Michael), the new centrality of context was seen as a direct substitution for earlier emphases on formulae and algorithms that were now viewed as being unnecessarily confusing. For all the teachers, there was a sense in which context was seen as enhancing accessibility to the mathematics which resulted in more convergence than with discussion although for different reasons. For Jennifer and Jonathan $_{2}$ it provided an approach to shaping discussion and thus making it more purposeful and aligned to learning objectives, whereas for Lucy and Michael there was a much greater sense that context functioned as a substitute for abstraction. Context provided something to discuss. The discussions were centred around a context.

Thus our data suggests that the implementation of the MiC scheme has had an effectimpacted on the practice of all four teachers in tangible ways. Certainly this has been achieved with respect to how they create the register through which they describe and evaluate their own practice, even though the scheme activated very different sorts of movements and outcomes between the two pairs of teachers. Within a project that is small scale and, in its early stages, our data shows that whilst teachers all made pedagogical shifts, and in a way that they would view as improvement, we would hesitate 
to in-claim thating they have reached a pre-determined point. Indeed we would suggest that the "point" they have reached is not singular and could be understood differently according to a variety of possible interpretive schemes. Or indeed, Žižek (2006) suggests that such a point is achieved through reading paradigmatic filters against each other. On a much larger scale, it could be inferred that any move to set curriculum guidance according to a specific agenda will not meet everyone's aspirations or sense of practice in a consistent way, although it might nevertheless be seen positively as providing the teachers with an alternative frame through which they might inspect and stimulate their evolving practice.

\section{PROBLEMS WITH CONSENSUS}

We have sought in this article to unsettle the ways in which curriculum reform is seen as shaping practice. We have argued that both teacher and curriculum change in the process of policy implementation. In the example provided ${ }_{2}$ teachers did not converge to a particular conception of teaching but rather evaluated their overall and cumulative teaching identity through a new filter, but a filter that could not be apprehended in its entirety from the outset. Our emphasis has been on how such discursive formulations evolve, rather than on supposing that these formulations can be checked out in relation to some supposed empirical truth of the teacher's everyday practice. We have argued that teacher responsiveness to policy is shaped through the unfolding discursive effects of successive paradigmatic adjustments. Hence, in many ways WCIT could be seen to be supportive of the philosophy of MiC, yet there were also clear differences and it would not be possible to adjudicate between which was best without fixing evaluative criteria that would favour one teaching philosophy or another. Teachers learnt about the MiC approach to teaching mathematics and "identified" with this approach, saw themselves in it, as it were, and began to describe their own practice in such terms, and through the filter of the new paradigm. The teachers engaged with and explored the two terms "discussion" and "context" as key instruments in better understanding how successive approaches contrasted with each other with respect to their practice. The terms provided conduits to more holistic yet still partial conceptions of the successive approaches. Laclau and Mouffe (2001) progress this position suggesting that human identity might be better understood as an amalgam of partial identifications with co-existing ideologies. Who I am, or my teacher identity, is a function of how I draw on elements from the alternative discourses in which I am immersed. But links between immediate tools and broader conceptions may be transitory or unreliable. As such weWe suggest that what might be seen by governments and researchers as the long march to improve standards through major holistic change, might better be understood as a succession of ideological changes which resist a unified conception of what improvement might be. Our argument is that mathematics education research and development, should seek to recognise difference in teachers' understandings, experiences and context of action and assist them in making informed professional judgements about how their practice might be developed in situ, rather than supposing that external evaluative judgements should be based on movement to a consensually preferred conception of teaching. 


\section{ACKNOWLEDGEMENTS}

This paper resulted from discussions with teachers and our colleagues who are involved in some related initiatives, in particular, a Gatsby funded project (Developing Mathematics through Contexts) being led by Frank Eade and Paul Dickinson, and an Economic and Social Research Council funded project (RES000221082) being led by Harry Torrance and Una Hanley. Elements of the theoretical model were developed within two studies carried out by Tony Brown, Olwen McNamara and Una Hanley for the ESRC (R000222409 and R000223073). We are indebted to Konrad Krainer for excellent editorial support.

\section{REFERENCES}

Althusser, L. (1971). Ideology and ideological state apparatuses. Lenin and philosophy and other essays. Trans. B. Brewster. London: New Left Books.

Bell, A. (1993). Some experiments in diagnostic teaching. Educational Studies in Mathematics, 24(1), 115137.

Blanton, M., Westbrook, S., \& Carter, G. (2005). Using Valsiner's zone theory to interpret teaching practices in mathematics and science classrooms. Journal of Mathematics Teacher Education, 8(1), 533.

Brown, M., Askew, M., Millett, A., \& Rhodes, V. (2003). The key role of educational research in the development and evaluation of the National Numeracy Strategy. British Educational Research Journal, 29(5), 655-667.

Brown, M., Millett, A., Bibby, T., \& Johnson, J. (2000). Turning our attention from the what to the how: the National Numeracy Strategy. British Educational Research Journal, 26(4), 457-472.

Brown, T. (2001). Mathematics education and language: interpreting hermeneutics and poststructuralism, (Revised second edition). Dordrecht, The Netherlands: Kluwer Academic Publishers.

Brown, T., Devine, N., Leslie, E. Paiti, M., Sila'ila'i, E., Umaki, S., \& Williams, J. (2006). Reflective engagement in cultural history: A Lacanian perspective on Pasifika teachers in New Zealand, Pedagogy, Culture and Society, 15(1).

Brown, T., Atkinson, D., \& England, J. (2006). Regulative discourses in education: a Lacanian perspective. Bern, Switzerland: Peter Lang.

Brown, T., \& McNamara, O. (2005). New teacher identity and regulative government: The discursive formation of mathematics teacher education. New York: Springer 2005.

Burns, C., \& Myhill, D. (2004). Interactive or inactive? A consideration of the nature of interaction in whole class teaching, Cambridge Journal of Education, 34(1), 35-49.

Cohen, D. (1990). A revolution in one classroom: The case of Mrs. Oublier. Educational Evaluation and Policy Analysis, 12, 327-345.

Cole, M. (1996). Cultural psychology: A once and future discipline. Cambridge, Mass: Belknap Press.

Department for Education and Employment: Standards and Effectiveness Unit (2001). Key Stage 3 National Strategy. Framework for teaching mathematics: Years 7, 8 and 9. London: Department for Education and Employment.

Derrida, J. (1978). Writing and difference. Chicago: Chicago University Press.

Fennema, E., \& Nelson, B. (Eds.) (1997). Mathematics teachers in transition. New Jersey: Lawrence Erlbaum Associates Inc.

Foucault, M. (1989). The archaeology of knowledge. London: Routledge.

Freudenthal, H. (1991). Revisiting mathematics education: China lectures. Dordrecht: Kluwer.

Fullan, M. (2001). The new meaning of educational change, 3rd edition New York: Teachers College Press.

Galton, M. (2002). A National Curriculum balance sheet. Education Review, 15(2), 15-21. 
Goos, M. (2005). A sociocultural analysis of the development of pre-service and beginning teachers' pedagogical identities as users of technology. Journal of Mathematics Teacher Education, 8(1), 35- 59.

Gravemeijer, K. (1994). Developing realistic mathematics education. Utrecht: CD-ßPress / Freudenthal Institute.

Hammersley, M. (1997). Some questions about evidence-based practice in education. Paper presented at the symposium on "Evidence-based practice in education" at the annual conference of the British Educational Research Association.

Handal, B., \& Herrington, A. (2003). Mathematics teachers' beliefs and curriculum reform. Mathematics Education Research Journal, 15(1), 59-69.

Hargreaves, D. (1996). Teaching as a research-based profession; possibilities and prospects. The Teacher Training Agency lecture. 1996, London: Teachers Training Agency.

Harrington, A. (1998). Whole class interactive teaching in mathematics. London: Teacher Training Agency.

Harris, S., Keys, W., \& Fernandes, C. (1997). Third international mathematics and science study: second national report part 1. Slough: National Foundation for Educational Research.

Hickey, D., Allison, A., \& Pellegrino, J. (2001). The motivational and academic consequences of elementary mathematics environments: Do constructivist innovations and reforms make a difference? American Educational Research Journal, 38(3), 611-652.

Krainer, K. (2003). Innovations in mathematics, science and technology teaching (IMST2). Initial outcome of a nation-wide initiative for upper secondary schools in Austria. Mathematics Education Review, 16, April 2003, 49-60.

Kynigos, C. \& Argyris, M. (2004). Teacher beliefs and practices formed during an innovation with computer-based exploratory mathematics in the classroom. Teachers and Teaching: theory and practice, 10(3), 247-273.

Laclau, E. (2005). On populist reason. London: Verso.

Laclau, E., \& Mouffe, C. (2001). Hegemony and socialist strategy: Towards a radical democratic politics. London: Verso.

de Lange, J. (1996). Using and applying mathematics in education. In A. Bishop, K. Clements, C. Keitel, J. Kilpatrick, \& C. Laborde. (Eds). 1996. International handbook of mathematics education, Part one. Dordrecht: Kluwer, pp. 49-97.

Lather, P. (2003). Applied Derrida: (Mis) reading the work of mourning in educational research, Educational Philosophy and Theory, 35(3) 257-270.

Lerman, S. (2000). A case of interpretations of 'social': A response to Steffe \& Thompson. Journal for Research in Mathematics Education, 31(2), 210-227.

Levi Strauss, C. (1989). The savage mind. London: Weidenfeld and Nicholson.

Lloyd, G. M. (1999). Two teachers' conceptions of a reform-oriented curriculum: Implications for mathematics teacher development. Journal of Mathematics Teacher Education, 2(3), 227-252.

Mouffe, M. (2005). On the political. London: Routledge.

Ng, S., Lopez-Real, F., \& Rao, N. (2003). Early mathematics teaching: the relationship between teachers' beliefs and classroom practices, Proceedings of the 2003 joint meeting of PME and PMENA, vol. 3. Honolulu, USA: University of Hawaii.

Piaget, J. (1971). Structuralism. London: Routledge and Kegan Paul.

Rancière, J. (2004). The politics of aesthetics. London: Continuum.

Remillard, J. (2000). Can curriculum materials support teachers' learning? Elementary School Journal, 11(4) 331-350.

Remillard, J. T. (2005). Examining key concepts in research on teachers' use of mathematics curricula. Review of Educational Research, 75(2), 211-246.

Remillard, J., \& Bryans, M. (2004). Teachers' orientations towards mathematics curriculum materials: implications for teacher learning. Journal for Research in Mathematics Education, 35(5), 352-388.

Remillard, J. T., \& Geist, P. K. (2002). Supporting teachers' professional learning by navigating openings in the curriculum. Journal of Mathematics Teacher Education, 5(1), 7-34.

Romberg, T. (1997). Mathematics in context: impact on teachers. In E. Fennema, \& B. Scott Nelson (Eds.) Mathematics teachers in transition. New Jersey: Lawrence Erlbaum Associates Inc.

Sahin, C., Bullock, K., \& Stables, A. (2002). Teachers' beliefs and practices in relation to their beliefs about questioning at Key Stage 2. Educational Studies, 28(4), 371-384.

de Saussure, F. (1966). A course in general linguistics. New York: McGraw-Hill. 
Schön, D. (2003). The reflective practitioner. London: Ashgate.

Senger, E. (1999). Reflective reform in mathematics: The recursive nature of teacher change. Educational Studies in Mathematics, 37(3), 199-221.

Simon, M., \& Tzur, R. (1999). Explicating the teacher's perspective from the researchers' perspectives: generating accounts of mathematics teachers' practice. Journal for Research in Mathematics Education, 30(3), 252-264.

Skott, J. (2001). The emerging practices of a novice teacher: The roles of his school mathematics images. Journal of Mathematics Teacher Education, 4, 3-28.

Steffe, L., \& Kieran, T. (1994). Radical constructivism and mathematics education, Journal for Research in Mathematics Education, 25(6), 711-733.

Swan, M. (2000). GSCE mathematics in further education: challenging beliefs and practices. The Curriculum Journal. 11(2), 199-223

Sztajn, P. (2003). Adapting reform ideas in different mathematics classrooms: beliefs beyond mathematics. Journal of Mathematics Teacher Education, 6 (1), 53-75.

Torrance, H., \& Pryor, J. (2001). Developing formative assessment in the classroom: using action research to explore and modify theory. British Educational Research Journal, 27(5), 615-631.

Tzur, R., Simon, M., Heinz, K., \& Kinzel, M. (2001). An account of a teacher's perspective on learning and teaching mathematics: implications for teacher development. Journal of Mathematics Teacher Education. 4(3), 227-254.

Van Zoest, L. R., \& Bohl, J. V. (2002). The role of reform curricular materials in an internship: The case of Alice and Gregory. Journal of Mathematics Teacher Education, 5, 265-288.

Walkerdine, V. (1984) Developmental psychology and the child-centered pedagogy. In J. Henriques, W. Holloway, C. Urwin, C. Venn, \& V. Walkerdine. Changing the subject: psychology, social regulation and subjectivity. London: Methuen.

Wilson, S. M., \& Goldenberg, P. (1998). Some conceptions are difficult to change: One middle school mathematics teachers' struggle. Journal of Mathematics Teacher Education, 1, 269-293.

Žižek, S. (2006). The parallax view. Cambridge, Mass: MIT Press. 